\title{
An experimental study of pyroxene crystallization during rapid cooling in a thermal gradient: application to komatiites
}

\author{
S. Bouquain ${ }^{1}$, N. T. Arndt ${ }^{1}$, F. Faure ${ }^{2}$, and G. Libourel ${ }^{2}$ \\ ${ }^{1}$ ISTerre, CNRS UMR5275, Université J. Fourier, BP53, 38041 Grenoble Cedex, France \\ ${ }^{2}$ Nancy Université, CNRS/INSU, CRPG, 15 rue Notre Dame des Pauvres, 54501 Vandoeuvre-lès-Nancy, France \\ Correspondence to: N. T. Arndt (nicholas.arndt@ujf-grenoble.fr)
}

Received: 30 November 2012 - Published in Solid Earth Discuss.: 27 March 2013

Revised: 5 March 2014 - Accepted: 20 March 2014 - Published: 9 July 2014

\begin{abstract}
To investigate the crystallization of pyroxene in spinifex-textured komatiites, we undertook a series of experiments in which compositions in the $\mathrm{CaO}-\mathrm{MgO}-\mathrm{Al}_{2} \mathrm{O}_{3}-\mathrm{SiO}_{2}$ CMAS system were cooled rapidly in a thermal gradient. Cooling rates were generally between 5 and $10^{\circ} \mathrm{Ch}^{-1}$, but some runs were made at $100-200^{\circ} \mathrm{Ch}^{-1}$; thermal gradients were between 10 and $20^{\circ} \mathrm{C} \mathrm{cm}^{-1}$. These conditions reproduced those at various depths in the crust of komatiite lava flow. The starting composition was chosen to have pigeonite on the liquidus, and most of the experimental charges crystallized zoned pigeonite-diopside crystals like those in komatiite lavas. An intriguing aspect of the experimental results was their lack of reproducibility. Some experiments crystallized forsterite, whereas others that were run under similar conditions crystallized two pyroxenes and no forsterite; some experiments were totally glassy, but others crystallized entirely to pyroxene. The degree of supercooling at the onset of pyroxene crystallization was variable, from less than $25^{\circ} \mathrm{C}$ to more than $110^{\circ} \mathrm{C}$. We attribute these results to the difficulty of nucleation of pyroxene under the conditions of the experiments. In some cases forsterite crystallized metastably and modified the liquid composition to inhibit pyroxene crystallization; in others no nucleation took place until a large degree of supercooling was achieved, and then pyroxene crystallized rapidly. Pigeonite crystallized under a wide range of conditions, at cooling rates from 3 to $100^{\circ} \mathrm{Ch}^{-1}$. The notion that this mineral only forms at low cooling rates is not correct.
\end{abstract}

\section{Introduction}

Pyroxenes in spinifex-textured komatiites display unusual textures and compositional variations that are probably related to the unusual conditions in which they crystallized (Fleet and MacRae, 1975; Arndt and Fleet, 1979; Donaldson, 1982; Arndt et al., 2008; Bouquain et al., 2008). In the internal zones of spinifex layers in thick komatiitic basaltic flows, two pyroxenes commonly are present. Where best developed, pyroxene spinifex texture consists of zoned needles with pigeonite cores and augite margins, commonly organized in clusters that are oriented approximately perpendicular to the flow contacts (Arndt and Fleet, 1979). Analysis of the compositions of these pyroxenes and of the rocks in which they are found has revealed some puzzling features. In many samples, pyroxene, usually pigeonite, can be inferred to be the liquidus phase on the basis of textural data, yet when the phase relations of the samples are determined experimentally, it is found that only olivine should have crystallized under equilibrium conditions (Campbell and Arndt, 1982). Bouquain et al. (2008) address this problem from a mineralogical and chemical point of view.

Faure et al. (2006) conducted a series of experiments in which they investigated the origin of spinifex textures. They addressed what has been called the spinifex paradox: the skeletal or dendritic habits of olivine crystals in spinifex textures resemble those in experimental charges that crystallized at high cooling rates $\left(50-100{ }^{\circ} \mathrm{Ch}^{-1}\right)$, but these textures are found deep in the interior of lava flows at depths where the cooling rate, limited by conduction through the flow top, must have been low $\left(<1\right.$ to $\left.5^{\circ} \mathrm{Ch}^{-1}\right)$. A novel aspect of the Faure et al. (2006) experiments is that they were conducted 
within the thermal gradient in the upper part of the $1 \mathrm{~atm}$ furnace, reproducing the gradient that exists in the upper parts of a lava flow. These experiments produced textures that closely resembled those in olivine spinifex-textured komatiites.

In this paper we present the results of experiments that build on the work of Faure et al. (2006). The major difference is in the composition of the experimental charges: whereas Faure et al. (2006) worked on an analogue in the CMAS $\left(\mathrm{CaO}-\mathrm{MgO}-\mathrm{Al}_{2} \mathrm{O}_{3}-\mathrm{SiO}_{2}\right)$ system with the ultramafic composition of komatiites, we worked on a less magnesian composition, one chosen so that pigeonite was the liquidus phase. With this choice we developed an experimental program designed to help understand the phase relations and habits of pyroxenes that crystallized under conditions like those in komatiitic lava flows.

\section{Experimental procedures}

The experiments described in this paper were conducted in the experimental petrology laboratory of Centre de Recherche Pétrographique et Géochimique in Nancy using the method developed by Faure et al. (2006). The starting composition in the CMAS system was chosen so as to have pigeonite on the liquidus and thus to be comparable to the komatiitic liquids that crystallize pyroxene spinifex textures. The starting material was prepared from pure oxides that were fused in platinum crucibles for $8 \mathrm{~h}$ at $1550^{\circ} \mathrm{C}$, a temperature well above the liquidus. The quenched material was then ground to a fine powder in an agate mortar.

For the isothermal crystallization experiments, the powder was mixed with a small amount of polyvinyl alcohol to produce a charge that could be suspended on a platinum wire. The charge was held at constant temperature for several hours in a $1 \mathrm{~atm}$ vertical quenching furnace, then quenched in water at the end of the experiment.

For the dynamic crystallization experiments, the powder was packed tightly into a graphite tube (length $5.5-6.5 \mathrm{~cm}$, diameter $4 \mathrm{~mm}$ ) that was placed in a GERO HTRV 70-250 vertical quenching furnace. Depending on the location of the tube above the hot spot of the furnace, the temperature gradient across the experimental charge varied from 8 to $40^{\circ} \mathrm{C} \mathrm{cm}^{-1}$. The temperature inside the furnace was measured by PtRh6-PtRh30 thermocouples that had been calibrated by melting gold and palladium wires. Through the course of the experiment, a stream of argon maintained a reducing atmosphere, preventing oxidation of the graphite tubes. In the standard procedure for dynamic crystallization experiments, called procedure 1 (Fig. 1), each experiment began with a stage at which the charge was held for 1-5 hours at a temperature of $1413^{\circ} \mathrm{C}\left(1505^{\circ} \mathrm{C}\right.$ at the bottom of the charge), about $27-119^{\circ} \mathrm{C}$ above the equilibrium liquidus temperature (see Table 1). During this phase, air trapped in the powder escaped, and as the charge compacted during melting, its length decreased from $5-6 \mathrm{~cm}$ to $2.5-4.5 \mathrm{~cm}$. The
Table 1. Isothermal crystallization experiments with composition A.

\begin{tabular}{cccccc}
\hline \# Run & $\begin{array}{c}T \\
\left({ }^{\circ} \mathrm{C}\right)\end{array}$ & $\begin{array}{c}\text { Melting } \\
\text { time }(\mathrm{h})\end{array}$ & $\begin{array}{c}\text { Fe-free } \\
\text { pigeonite }\end{array}$ & $\begin{array}{c}\text { Ca-rich } \\
\text { diopside }\end{array}$ & Silica \\
\hline SB632 & 1320 & 102 & + & + & + \\
SB633 & 1340 & 24 & + & + & + \\
SB618 & 1348 & 100 & + & + & + \\
SB626 & 1354 & 15 & + & + & - \\
SB625 & 1359 & 7 & + & - & - \\
SB627 & 1364 & 7.5 & + & - & - \\
SB615 & 1379 & 15.3 & + & - & - \\
SB613 & 1385 & 11.2 & + & - & - \\
SB623 & 1388 & 9 & - & - & - \\
SB624 & 1389 & 14.7 & - & - & - \\
SB622 & 1394 & 96 & - & - & - \\
SB611 & 1486 & 1.3 & - & - & - \\
\hline
\end{tabular}

Notes: + denotes present; - denotes absent.

charge was then cooled at a constant rate that varied from 3 , 5, 10,100 to $200^{\circ} \mathrm{Ch}^{-1}$ depending on the experiment. The temperature gradients across the experimental charge were around $20^{\circ} \mathrm{C} \mathrm{cm}^{-1}$ and matched those calculated in the upper part of a komatiitic flow.

The intent of this procedure was to progressively crystallize the charge, downwards from the cooler top to the warmer base, thus simulating progressive solidification in the upper crust of a lava flow. As described by Faure et al. (2006), this procedure provides important information about the kinetics of crystallization under conditions that reproduce those in natural lavas.

During the experiments labelled CPX15-26, a modified procedure, called procedure 2 (Fig. 1), was used: the experimental charges were first heated to a higher temperature of $1470{ }^{\circ} \mathrm{C}\left(1555^{\circ} \mathrm{C}\right.$ at the bottom of the charge $), 84-169^{\circ} \mathrm{C}$ above the liquidus, for 2 hours, and then the temperature was rapidly lowered to bring the top of the capsule (the cool end) to a temperature about $12{ }^{\circ} \mathrm{C}$ above the liquidus for 1 hour. The high-temperature fusion resulted in optimal homogenization of the charge and the elimination of any relict solid phases. In the experiments labelled CPX04 and CPX06-14, the charges were held at a constant temperature $119^{\circ} \mathrm{C}$ above the liquidus for several hours. We also performed two experiments with two other procedures (procedures 3 and 4, Fig. 1), in order to be sure to crystallize pyroxene. In procedure 3 , the experimental charge was first heated to a high temperature $\left(1525^{\circ} \mathrm{C}\right.$ at the bottom of the charge) for 1 hour, and then the temperature was rapidly lowered to bring the bottom of the capsule to a temperature about that of the liquidus. The charge was then cooled at a constant rate of $3^{\circ} \mathrm{Ch}^{-1}$. In procedure 4 , the initial heating temperature was very low: $1401^{\circ} \mathrm{C}$ at the bottom of the charge, at the hot end. The temperature before the cooling step was also very low: $1325^{\circ} \mathrm{C}$ at the bottom of the charge. 

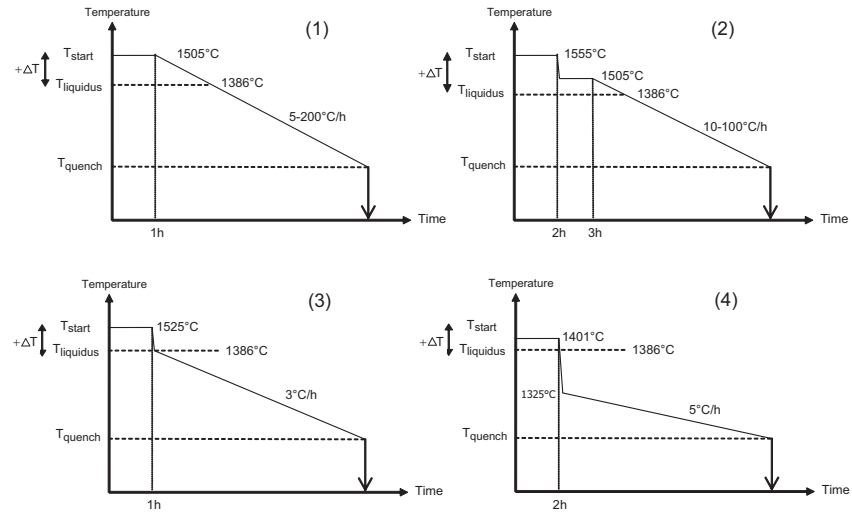

Figure 1. Details of the four cooling procedures used during dynamic crystallization experiments.

At the end of each experiment, the charge was quenched in distilled water. The tube and its experimental charge were then cut along the long axis, imbedded of resin, polished, and then analyzed using an electron microprobe (Cameca SX100 at the University Henri Poincaré, Nancy, France) and a microfluorescence spectrometer (Eagle III at the University of Grenoble). Electron microprobe analyses were performed with a Cameca SX100 at Nancy Université (Service Commun de Microscopies Electroniques et de Microanalyses X) using a beam current of $10 \mathrm{nA}$, an accelerating voltage of $15 \mathrm{kV}$ and a focused beam $(1-2 \mu \mathrm{m})$ with a 20 s peak counting time.

An attempt was made to terminate each experiment at a temperature calculated to quench to glass an interval of uncrystallized liquid in the lower (hotter) end of the charge: in practice this proved to be very difficult, as described in the following section. Figure 2 illustrates a typical experimental charge. The lower (hotter) third consists of sparse pigeonite crystals in translucent glass that fractured during quenching. Elongate crystals of pyroxene become increasingly abundant toward the cooler top of the charge, and the upper portion is totally crystallized to pigeonite, augite and a silica mineral, probably tridymite. The temperatures of initial crystallization of each of these phases can be determined with precision by measuring the position in charge, which was previously calibrated for temperature (Faure et al., 2006). During the experiment CPX15 (Fig. 2), a bubble formed at the bottom of the load because of incomplete outgassing of powder during the initial phase of high-temperature fusion. This happened during several experiments, but does not significantly affect their interpretation (this problem was not encountered during the experiments of Faure et al. (2006), who worked on a less viscous komatiitic composition). In the case of CPX15, the experience was not terminated soon enough to preserve crystal-free glass below the crystallization front. The temperature of the first appearance of pigeonite is therefore a minimum temperature, and the estimated degree of nominal undercooling is a maximum value.

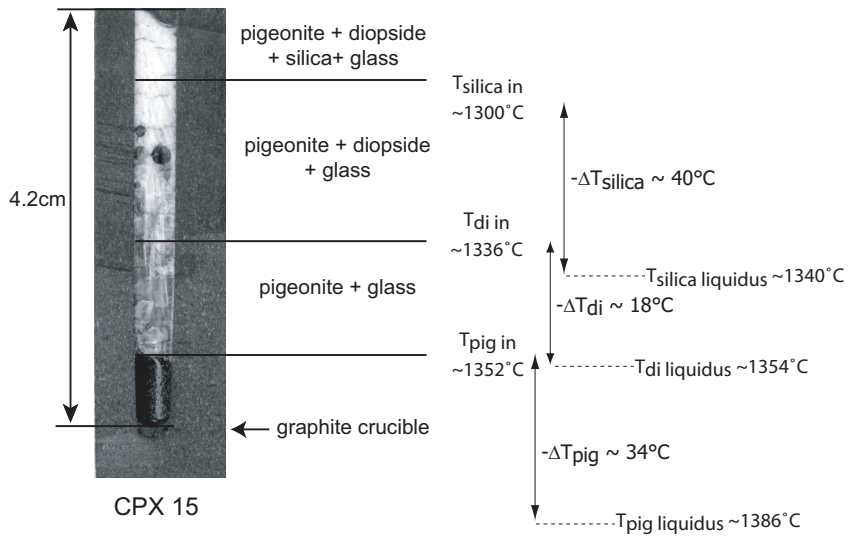

Figure 2. Typical experimental charge. The charge was cut along its length, then polished and scanned. Temperatures of appearance of crystalline phases are compared to their liquidus temperature determined in isothermal experiments

The results of the isothermal crystallization experiments are summarized in Table 1, and those of the dynamic cooling experiments are given in Table 2.

\subsection{Experimental problems}

Many experiments did not work as intended, with variable consequences as described in the following paragraphs.

1. The early experiments were carried out in thin graphite tubes that partially disintegrated in the course of the run. In some cases multiple fine, delicate forsterite crystals penetrated the walls of the capsule and grew outwards to form remarkable porcupine-like structures. Although no detailed information about the crystallization sequence is provided by such experiments, they indicate that forsterite nucleated and grew rapidly at relatively high temperatures, as in the case of experiment CPX06 in which forsterite grew in part of the tube that was at a temperature of $1406^{\circ} \mathrm{C}$ at the time of quenching.

2. In several experiments, empty segments of varying size (5-30 $\mathrm{mm}$ long) were distributed throughout in the capsule, most commonly near the base or in the middle. We interpret these empty segments as air bubbles that were trapped in the liquid phase during initial melting at high temperatures. Because of the small size of the capsules and the relatively high viscosity of the molten starting material, air trapped in the powder could not always be evacuated. When the air bubble is located at the bottom of the capsule, it has little effect on the course of the experiment. In some experiments, small volumes of melt (a few cubic millimeters) were isolated at the bottom of the capsule, or at the top. The products of crystallization of these melts can be very different from those in the main volume of melt. For example, we observed 


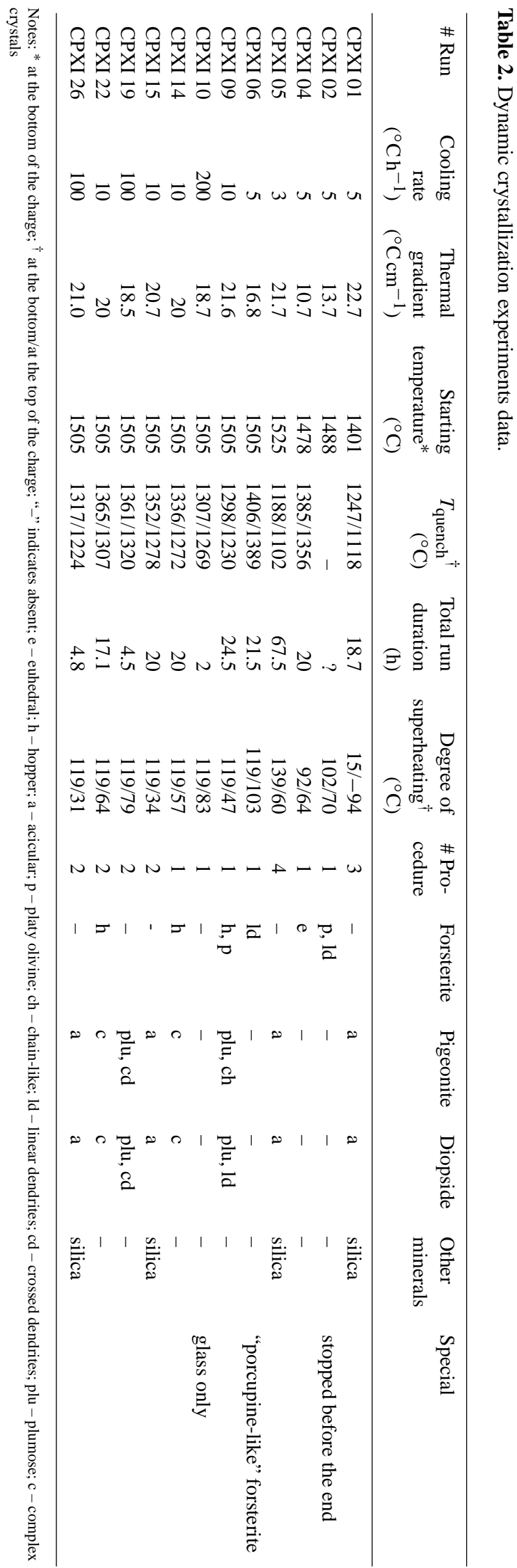

anorthite and spinel in experiment CPX11, and very $\mathrm{Ca}-$ rich diopside in experiment CPX07.

3. It was very difficult to stop the experiments before the crystallization front had reached the base of the capsule. Some experiments were almost entirely glassy or contained only isolated forsterite crystals, and two notable examples contained crystal-free glass in the lower portion: most experiments, however, were entirely crystallized. As discussed below, we infer that once the pyroxene nucleates, it grows rapidly to fill most, or all, of the capsule.

4. The experiments were not reproducible. The phases that crystallized, and the order in which they appeared, were not systematic but varied from one experiment to another, even when the experimental conditions were similar or identical. For example, experiments CPX14 and CPX15 were conducted at identical cooling rates $\left(10^{\circ} \mathrm{Ch}^{-1}\right)$ and in the same thermal gradient $\left(20^{\circ} \mathrm{C} \mathrm{cm}^{-1}\right)$. The temperatures at capsule ends at the time of quenching were similar: $1336^{\circ} \mathrm{C}$ and $1352^{\circ} \mathrm{C}$ at the hot end and $1272{ }^{\circ} \mathrm{C}$ and $1278^{\circ} \mathrm{C}$ at the cool end. Yet despite these similar conditions, forsterite is present in experiment CPX14 (as isolated hopper crystals) but is absent in experiment CPX15. In addition, the morphologies of pyroxene are very different in the two experiments, as described in the section presenting the results of the dynamic cooling experiments.

\section{Experimental results}

\subsection{Isothermal crystallization experiments}

Isothermal crystallization experiments were employed to determine the liquidus phase relations of the starting material. The material used in the dynamic cooling experiments (Table 1) had pigeonite in the liquidus, and appropriately only this mineral crystallized in experiment SB613, which was conducted at $1385^{\circ} \mathrm{C}$. The crystals are rounded, with sizes ranging from 5 to $30 \mu \mathrm{m}$. The calcium content of this pigeonite is very low, around $3.1 \mathrm{wt} \% \mathrm{CaO}$. The nucleation was heterogeneous and took place on the platinum wire, on the walls of the charge, on a platinum bead that became detached during the preparation of the experiment, and on an air bubble. In an experiment conducted at $1388^{\circ} \mathrm{C}$, the entire charge (SB623) is glassy. The temperature liquidus is therefore $1386 \pm 1{ }^{\circ} \mathrm{C}$. Only pigeonite crystallizes at temperatures down to $1359^{\circ} \mathrm{C}$, and its Ca content increases gradually from $3.1 \%$ to $6.0 \mathrm{wt} \%$ (SB625) (Table 3). At $1354^{\circ} \mathrm{C}$, Ca-poor diopside appears as abundant, rounded, very small crystals, each a few microns across. The rate of nucleation of diopside was evidently higher than that of pigeonite. A silica mineral, probably tridymite, joined the assemblage to $1348^{\circ} \mathrm{C}$ (SB618). When it first appears, this mineral has an 
Table 3. Liquid and mineral compositions.

\begin{tabular}{|c|c|c|c|c|c|c|c|c|}
\hline & \multirow{2}{*}{$\begin{array}{r}\text { Starting material } \\
\text { (composition \#8) } \\
\text { glass }\end{array}$} & \multicolumn{4}{|c|}{$\begin{array}{l}\text { Isothermal crystallization } \\
\text { experiments \#SB633 }\end{array}$} & \multicolumn{3}{|c|}{$\begin{array}{l}\text { Dynamic crystallization } \\
\text { experiments \#CPX15 }\end{array}$} \\
\hline & & glass & pigeonite & diopside & silica & glass & pigeonite & diopside \\
\hline $\mathrm{MgO}$ & 21.6 & 16.6 & 35.8 & 24.6 & 0.0 & 18.1 & 37.2 & 28.2 \\
\hline $\mathrm{Al}_{2} \mathrm{O}_{3}$ & 1.6 & 3.6 & n.d. & 0.1 & 0.2 & 2.7 & 0.1 & 0.1 \\
\hline $\mathrm{SiO}_{2}$ & 62.3 & 63.8 & 59.9 & 57.3 & 99.4 & 64.4 & 60.9 & 58.3 \\
\hline $\mathrm{CaO}$ & 14.7 & 15.4 & 5.7 & 18.7 & 0.1 & 16.3 & 3.9 & 14.9 \\
\hline
\end{tabular}

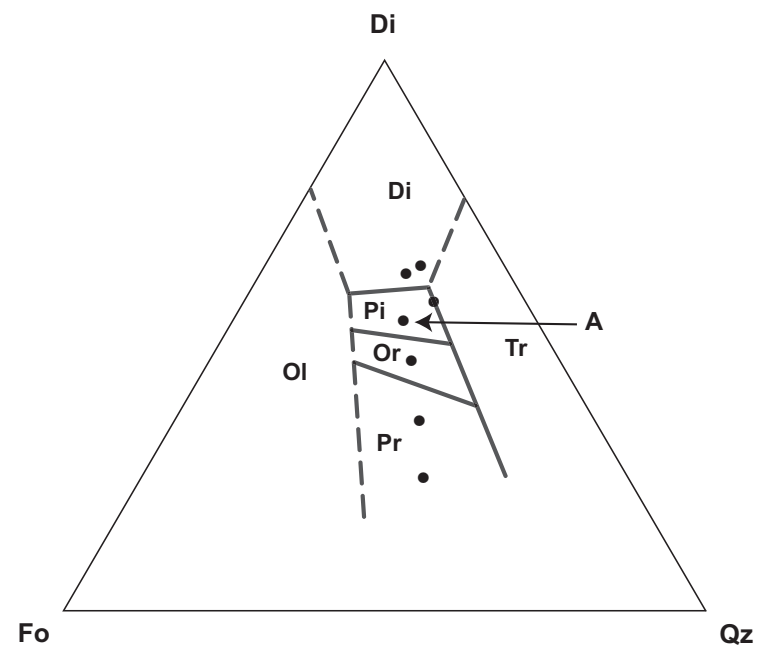

Figure 3. Starting material compositions plotted in the forsteritediopside-silica (Fo-Di-Qz) pseudo-ternary diagram. Liquid compositions are projected from anorthite. Phase boundaries and reaction curves are shown in more detail in Fig. 4. Composition A was used in dynamic crystallization experiments.

elongate anhedral habit, but at lower temperature it forms euhedral laths that are highly elongated along the $c$ axis. The solidus temperature was not determined because there was still a fraction of the liquid at $1277^{\circ} \mathrm{C}(\mathrm{SB} 630)$.

We also performed six other series of isothermal crystallization experiments, each with a different starting material composition (Fig. 3). The results are shown in Fig. 4. This phase diagram represents the $5 \%$ An plane in the forsteritediopside-anorthite-silica system, which is part of the CMAS system. The pigeonite field is small - its size decreases with increasing anorthite component and disappears completely at moderate $\mathrm{Al}_{2} \mathrm{O}_{3}$ contents (Longhi and Boudreau, 1980). The sensitivity of pigeonite stability to the $\mathrm{Al}_{2} \mathrm{O}_{3}$ content may explain some of the erratic experimental results.

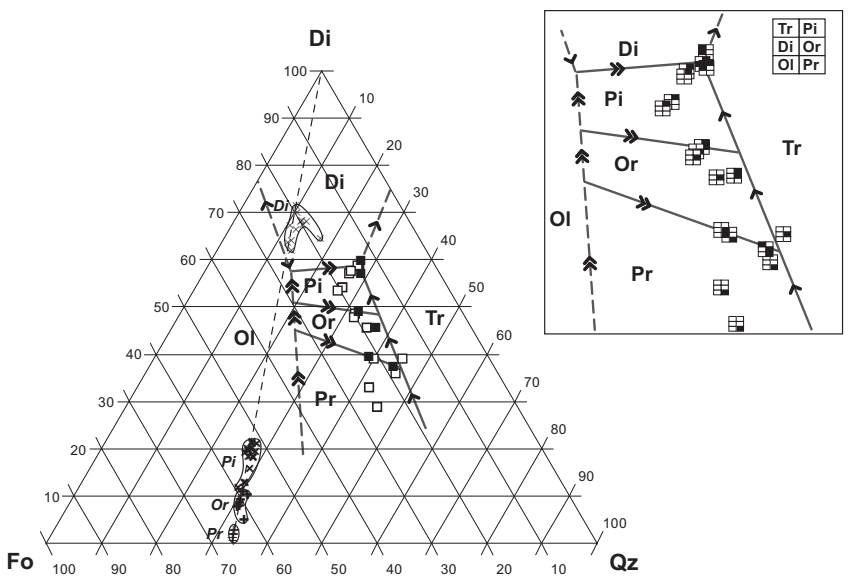

Figure 4. Liquidus boundaries in the system forsterite-diopsideanorthite-silica. Represented join is Fo95An05-Di95An05SiO295An05: this plane is parallel to the pseudo-ternary Fo$\mathrm{Di}-\mathrm{SiO}_{2}$ diagram and contains $5 \%$ An. Squares are liquid compositions saturated with two crystalline phases (white squares) or three crystalline phases (black squares). Analyses of pyroxene crystals are shown. Single arrows indicate cotectic curves; double arrows indicate reaction curves.

\subsection{Dynamic crystallization experiments}

Major results of dynamic crystallization experiments are summarized graphically in Fig. 5. Associated data are in Table 2 .

Forsterite: in many of the dynamic crystallization experiments, we observed forsterite in addition to one or two pyroxenes. Forsterite crystallized in approximately one-third of the experiments, an unexpected result because this mineral did not crystallize in any of the isothermal crystallization experiments. In some experiments it coexists with tridymite and is evidently not an equilibrium phase in the starting material. Forsterite was the only crystalline phase in four experimental runs (Table 2), all conducted at a moderate cooling rate of $5{ }^{\circ} \mathrm{Ch}^{-1}$. In experiments with higher cooling rates $(100$ $200^{\circ} \mathrm{Ch}^{-1}$ ), forsterite did not appear. In most experiments, the forsterite crystals have euhedral, or elongate platy, or dendritic habits (Fig. 6). In the runs labelled CPX03 and CPX04, conducted with a low thermal gradient $\left(10^{\circ} \mathrm{Ccm}^{-1}\right)$, a few 


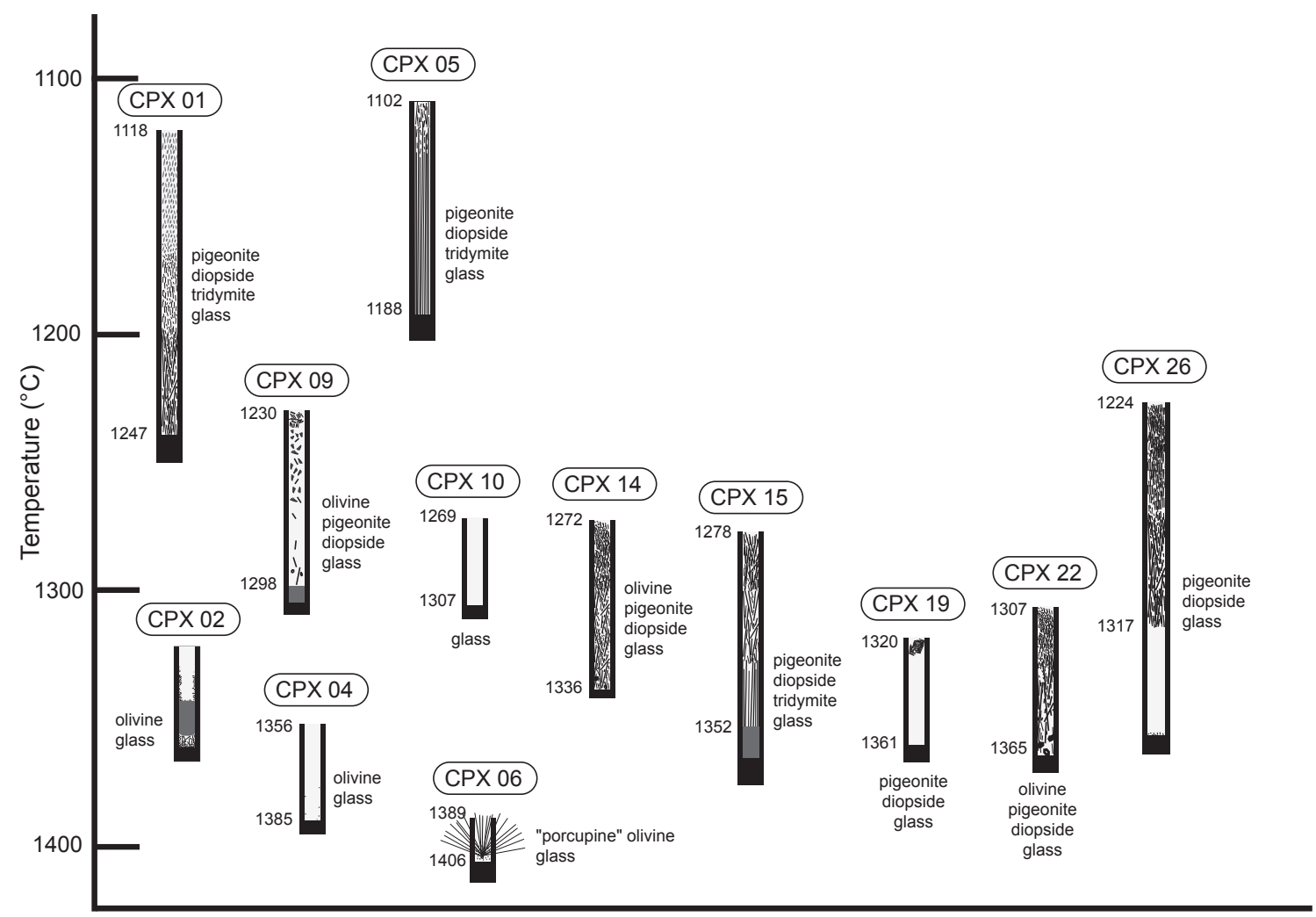

Figure 5. Textural and mineralogical data from dynamic crystallization experiments. The graphite capsules are represented in black. Minerals are in black and lie in a glass shown in white. Grey fields are bubbles.

euhedral forsterite crystals with well-developed faces were observed at the base of the capsule (Fig. 6f). These experiments were quenched at about $1380^{\circ} \mathrm{C}$. The crystals contain about $0.9 \mathrm{wt} \% \mathrm{CaO}$, and surrounding glass has a forsteritedepleted composition, with lower $\mathrm{SiO}_{2}$ and higher $\mathrm{CaO}$ than the starting material.

In the two other experiments (CPX02 and CPX06), forsterite displays dendritic morphologies. The CPX02 experimental charge contains two parts: the $12 \mathrm{~mm}$ long lower part contains millimeter-sized elongate platy crystals with fine dendrite tips (Fig. 6b), and the $10 \mathrm{~mm}$ long upper part displays fine dendritic crystals (Fig. 6a). The latter nucleated on the capsule border, and are 100-300 $\mu \mathrm{m}$ long. The residual glass is strongly zoned around the forsterite crystals. CPX06 was not a successful run because the graphite capsule partially disintegrated, but in this experiment olivine grew at a very high temperature $\left(1406^{\circ} \mathrm{C}\right)$.

In experiments in which olivine coexists with pyroxene, the forsterite habit is generally similar to that in pyroxenefree runs, but in some case the borders of the crystals are rounded and embayed. Experiment CPX09 (Fig. 7) contains good examples of the variety of textures deployed by this mineral. In the lower part of the capsule, forsterite has a hopper or platy habit (Fig. 8c), whereas at the top of the capsule, it forms crystals with a complex, irregular, elongate morphol- ogy. Pigeonite and diopside grow around forsterite crystals (Fig. 8a and b). Some of the forsterite crystals are rounded and embayed, particularly where they are surrounded by smaller pigeonite and diopside crystals (Fig. 8a and b).

The forsterite crystals have high $\mathrm{CaO}$ contents, up to $0.5 \%$ in solid crystals and up to $1.5 \%$ in fine dendrites. The glass surrounding the crystals is depleted in the forsterite component, with low $\mathrm{SiO}_{2}$ and high $\mathrm{CaO}$ compared to starting material.

Pyroxene crystallized over a large range of temperatures, from 1365 to $1102^{\circ} \mathrm{C}$. In these experiments, cooling rates were between 3 and $100{ }^{\circ} \mathrm{Ch}^{-1}$, and the temperature gradient was $20^{\circ} \mathrm{C} \mathrm{cm}^{-1}$. One or two pyroxenes, pigeonite and diopside, crystallized in about two-thirds of the experiments. The two pyroxenes coexist in all experiments except for CPX08, the unsuccessful experiment with porcupine-like forsterite, where only diopside crystallized. Pigeonite and diopside were present over the entire temperature range, but diopside appears in only one experiment at a temperature over $1336^{\circ} \mathrm{C}$. Isolated crystals of pigeonite were observed in only one run, CPX 15; in all others this mineral occurs as the cores of zoned crystals with diopside margins.

Pyroxene usually crystallizes as acicular, zoned crystals, each with a core of pigeonite and a border of augite (e.g., Fig. 8e and f) as in spinifex-textured komatiite. 

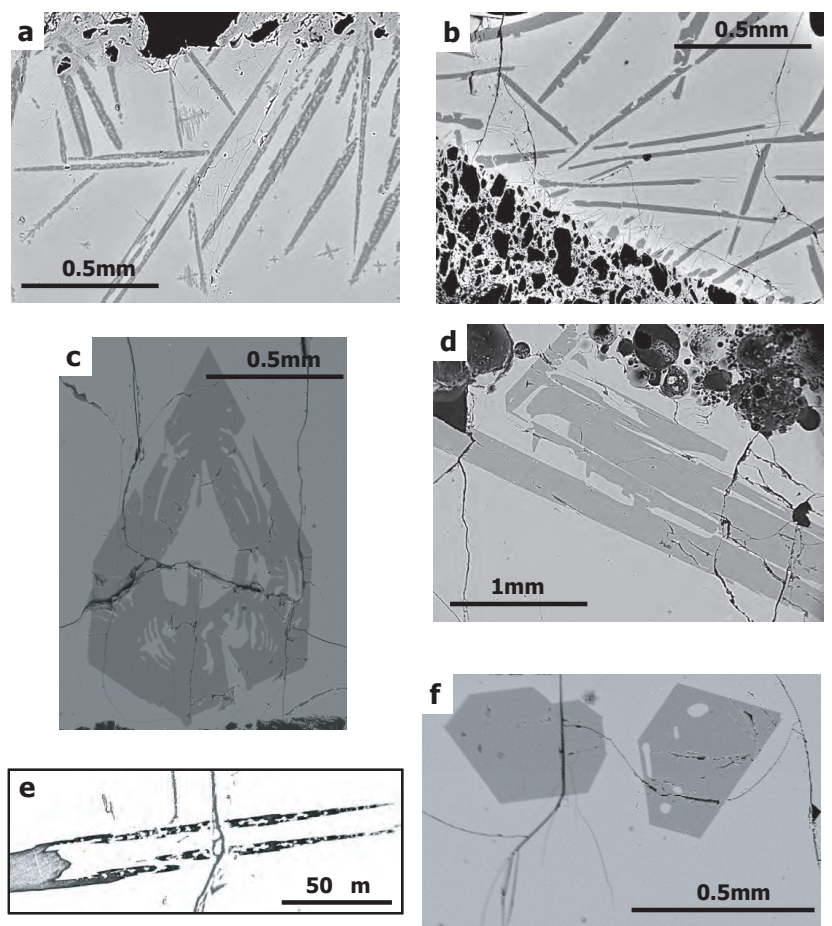

Figure 6. Photomicrographs showing olivine morphologies observed in dynamic crystallization experiments. Nomenclature is from Donaldson (1976) and Faure et al. (2003), respectively: (a) chain olivine/swallowtail shape (CPX02), (b) branching olivine/swallowtail shape (CPX02), (c) hopper olivine (CPX09), (d) plate olivine/swallowtail shape (CPX09), (e) detail of dendritic tail of a swallowtail olivine crystal (CPX02), and (f) polyhedral olivine (CPX04)

In experiment CPX09, the larger zoned crystals have a "plumose" morphology (Fig. 8c) while the smaller diopside crystals have a more euhedral, prismatic or chain-like morphology (Fig. 8b). Similar morphologies have also been reported in natural komatiites (Arndt and Fleet, 1979). In other experiments such as CPX19 and CPX22, pyroxene forms complex or cross-shaped dendrites (Fig. 8d). In the two experiments conducted under similar conditions but with contrasting results, the pyroxene morphologies were very different. As mentioned above, forsterite crystallized as isolated hopper crystals in experiment CPX14, but was absent in experiment CPX15. In experiment CPX14, skeletal prismatic to highly dendritic grains of pyroxene crystallized between larger forsterite grains, like those illustrated in Fig. 8b and c. In experiment CPX15, pyroxene crystals fill the entire charge, mainly as elongated needles oriented parallel to one another and approximately parallel to the walls of the capsule. As illustrated in Fig. 2, in the lower, hotter, part of the capsule, pigeonite occurs alone as acicular, dendritic crystals; in the upper, cooler part, diopside and pigeonite crystallized as a dense mat of fine, zoned, dendritic crystals. In the uppermost part, tridymite appears in the matrix (Fig. 2).

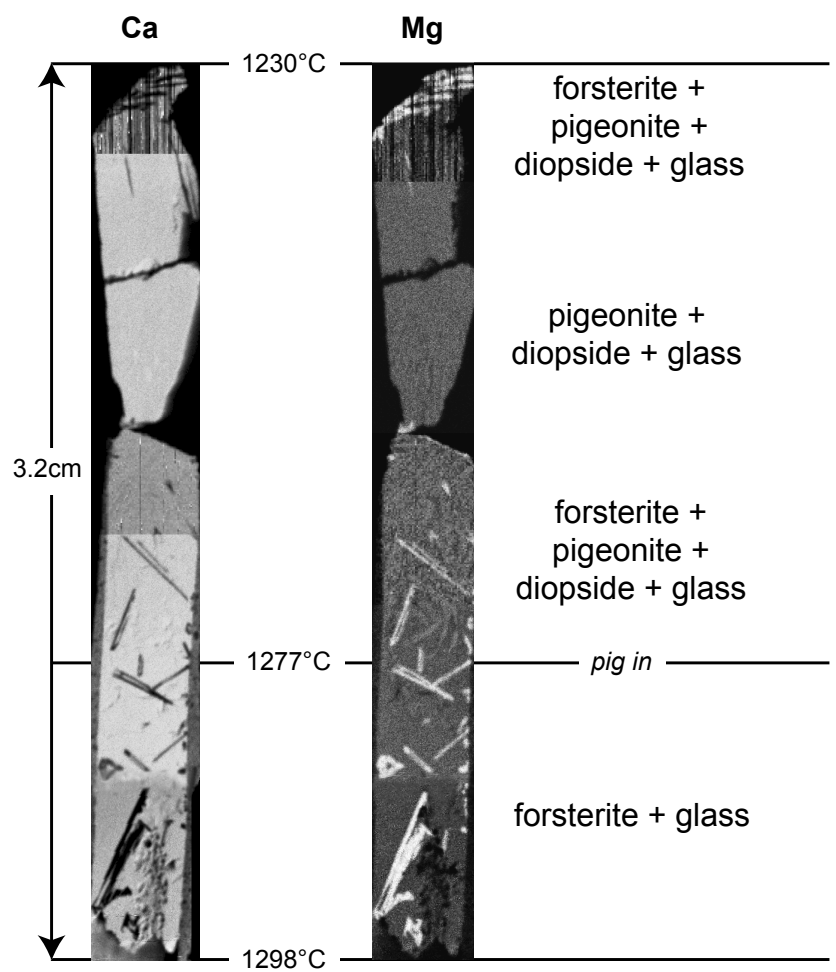

Figure 7. Microfluorescence images of the experimental charge labelled CPX09. Indicated temperatures are quenching temperature.

In experiment CPX22, pigeonite and diopside crystallize as zoned cross-shaped dendrites. These are found in the lower part of the capsule, at a temperature of $1365^{\circ} \mathrm{C}$, $9^{\circ} \mathrm{C}$ above diopside liquidus temperature as determined in isothermal experiments.

Representative pyroxene compositions are given in Table 3 . The $\mathrm{CaO}$ content of pigeonite varies from $3.9 \%$ in the core of a grain that crystallized at the highest temperature to an apparent $9 \%$ in a grain in one of the lowest-temperature runs. The high value could be a bad analysis resulting from a mixed signal between the pigeonite core and the diopside border of a fine zoned crystal.

Most diopside grains have $\mathrm{CaO}$ contents between 13 and $20 \%$, significantly less than that in stoichiometric diopside $\left(\mathrm{CaMgSi}_{2} \mathrm{O}_{6}\right.$ contains $\left.25.9 \% \mathrm{CaO}\right)$. In the run CPX08, where diopside formed complex dendritic crystals, the cores are unusually calcic $(25 \%)$ and the borders are rich in $\mathrm{Al}$ $(2 \%)$.

Other minerals: tridymite is present in about one-third of experimental charges, irrespective of the presence of forsterite. Other crystalline phases include Ca-rich diopside (CPX07), anorthite (CPX11) and spinel (CPX11). In all three cases, these minerals crystallized in small volumes of liquid, commonly isolated from the main mass of the charge, and they are not representative of the normal crystallization sequence. 

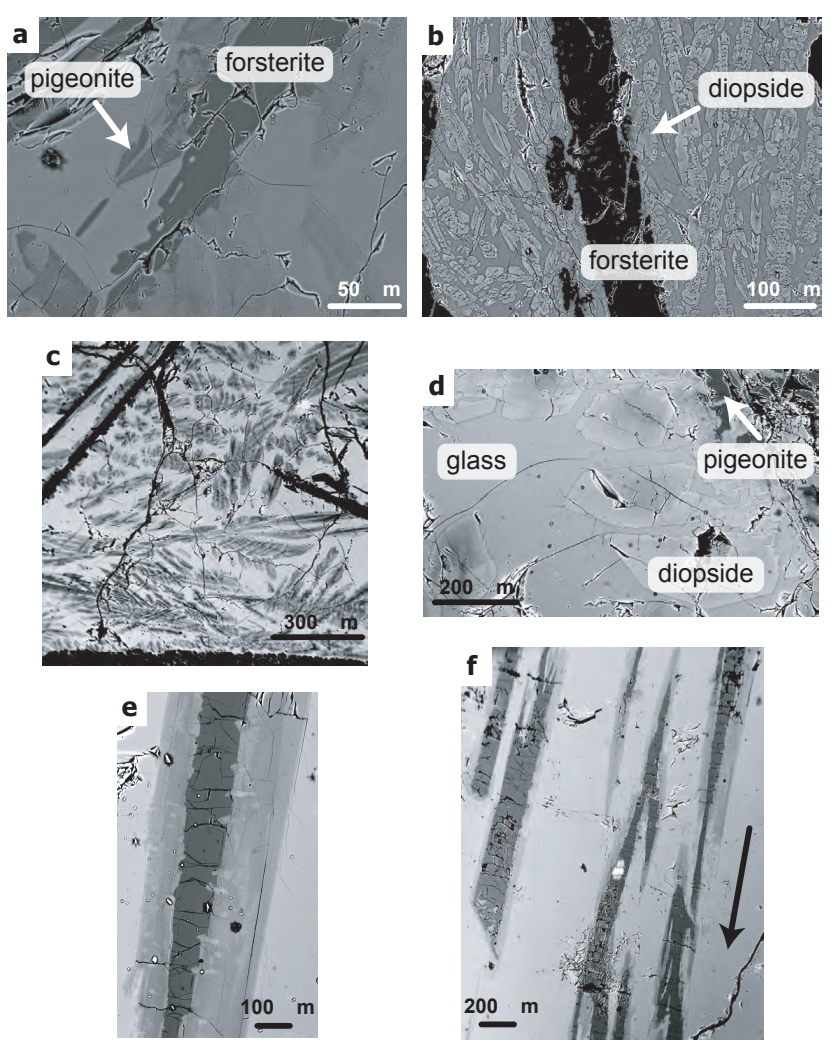

Figure 8. Photomicrographs showing pyroxene morphologies observed in dynamic crystallization experiments: (a) dendritic pigeonite growing on a rounded forsterite crystal (CPX09), (b) chain diopside nucleation and growth on a plate olivine crystal, (c) plumose zoned pyroxene between platy olivine crystals (CPX09), (d) dendrites on complex pyroxene crystal (CPX14), and (e, f) zoned pyroxene needles, growing downwards and parallel to each other.

\section{Discussion}

Perhaps the most significant aspect of the results is their unpredictability. Although other experiments have explored the crystallization of pyroxene under conditions of rapid cooling, none has coupled this with the presence of a thermal gradient. Under such conditions the kinetics of nucleation and crystallization come into play and strongly influence the sequence and extent of crystallization, or, under some circumstances, the very presence or absence of certain phases. For example, forsterite, a phase absent under equilibrium conditions, crystallized in one-third of our experiments. It is present in one run (CPX 06) at a temperature of $1406^{\circ} \mathrm{C}$ but absent from another run (CPX10) that was quenched at far lower temperatures, from 1307 to $1269^{\circ} \mathrm{C}$. In the latter, the entire charge was glassy and no crystalline phases are present. Another example is the contrasting phase assemblages in two experiments: CPX14, which crystallized forsterite, and CPX15, which did not, as discussed in the preceding section. Finally, diopside is present at the bottom of the capsule CPX22, at a

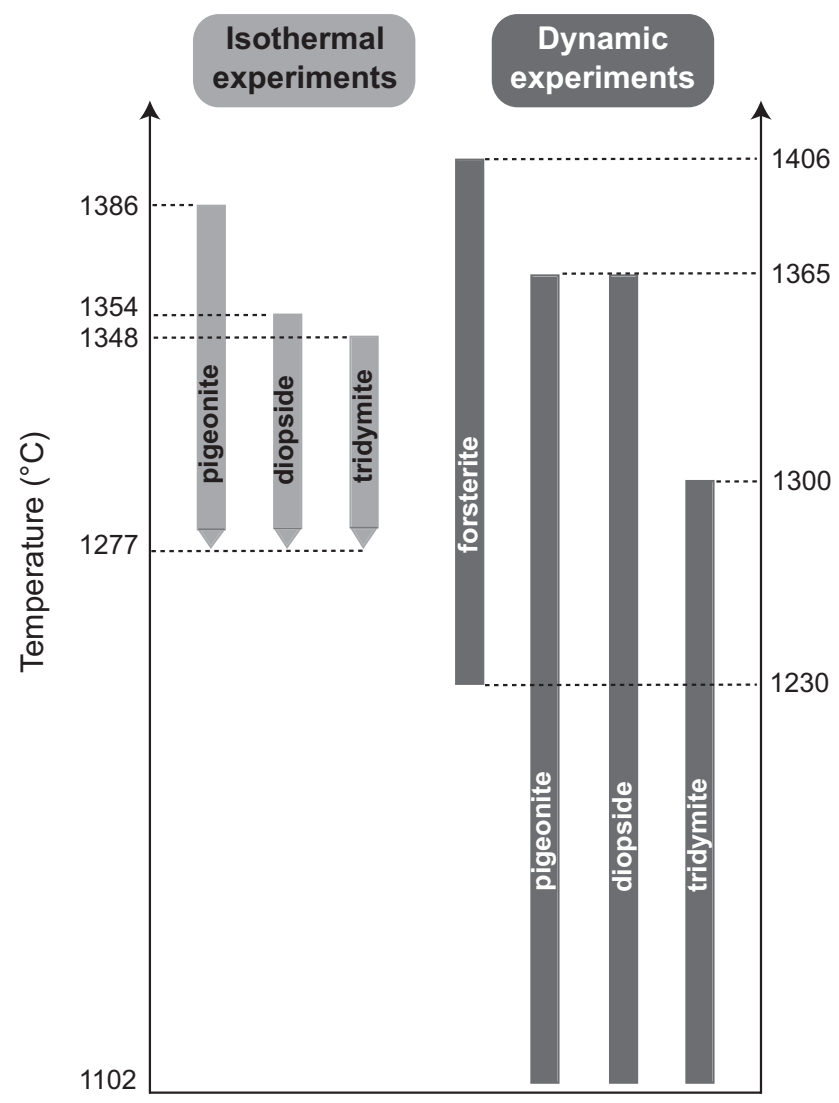

Figure 9. Range of crystallization temperatures of silicate phases observed in both isothermal and dynamic experiments.

temperature of $1365^{\circ} \mathrm{C}, 9^{\circ} \mathrm{C}$ above its liquidus temperature. This apparently high value, if not due to an analytical problem, may be the result of almost complete crystallization in the experimental charge. Crystallization of forsterite and pigeonite may have produced an evolved liquid from which diopside then crystallized. Temperature of crystallization of diopside from this liquid may be slightly different from diopside equilibrium liquidus temperature.

Another interesting result is the difficulty we experienced in quenching the runs before they had entirely crystallized. In the earlier experiments carried out by Faure et al. (2006) on charges of more magnesian compositions, it was relatively simple to terminate the experiment at a stage when a totally glassy segment was preserved in the lower, hotter, portion of the capsule, but in our experiments, either the charge was totally glassy (e.g., CPX 10) or crystals were present throughout the charge.

The explanation of these effects probably can be found in the kinetics of crystallization and particularly in the difficulty of nucleation of pyroxene. Lofgren (1983) and Kinzler and Grove (1985) have shown, for example, that under conditions of rapid cooling (but in the absence of a thermal gradient), the temperature of appearance of augite and pigeonite was depressed when the cooling rate exceeded $10^{\circ} \mathrm{Ch}^{-1}$. Kinzler 
and Grove (1985) found that, at a cooling rate of $50^{\circ} \mathrm{Ch}^{-1}$, the nucleation of augite was delayed by $100^{\circ} \mathrm{C}$ and that of pigeonite by $250^{\circ} \mathrm{C}$. Faure et al. (2006) observed a similar effect in the presence of a thermal gradient. In experiments conducted at a cooling rate of $5^{\circ} \mathrm{Ch}^{-1}$, the diopside liquidus was depressed by about $46^{\circ} \mathrm{C}$. A significant difference exists: whereas the depression of the forsterite liquidus was very small in the normal dynamic crystallization experiments, Faure et al. (2006) monitored a $\sim 50^{\circ}$ depression in the thermal-gradient experiments.

In our experiments we observed a somewhat contrary effect: as summarized in Figs. 7 and 9, forsterite appears in our dynamic-cooling thermal-gradient experiments as an apparently metastable phase at temperatures above the liquidus measured in the equilibrium experiments. Even if the presence of porcupine-like olivine in flawed experiment CPX06 is discounted, the crystals in experiment CPX04 cannot be so easily dismissed. In the latter experiment, the olivine has the euhedral morphology illustrated in Figure $4 \mathrm{f}$ and is found at the base of the capsule. It is possible that these crystals nucleated in the upper, cooler portion of the capsule, but since the thermal gradient was low, the temperature even at this end was high, at $1356^{\circ} \mathrm{C}$. At the hotter base of the capsule where the euhedral crystals were found, the temperature at the time of quenching was $1385^{\circ} \mathrm{C}$, essentially the same as the $1386^{\circ} \mathrm{C}$ liquidus under equilibrium conditions.

In experiment CPX09, shown in Fig. 7, olivine persists from the base to the top of the capsule. At the hot base (temperature at quenching $=1298^{\circ} \mathrm{C}$ ), it forms the stubby to moderately elongate crystals shown in Fig. $4 \mathrm{c}$ and d; in the middle it occurs as finer, more elongate plates; and at the top (temperature at quenching $=1230^{\circ} \mathrm{C}$ ) it occurs as large plates with smoothly rounded or embayed margins, as shown in Figure 5a and $b$. The olivine crystals appear to have grown on the borders of the capsules and on small particles of platinum, and apparently nucleated heterogeneously. Several lines of evidence indicate that the forsterite is metastable: first and most obviously, its absence in the isothermal experience conducted on the same starting material; second, its coexistence with tridymite in one experiment (CPX25); third, the rounded and embayed margins of the grains at the top of capsule CPX09, which we interpret to indicate that the crystals were reacting with the liquid.

The presence or absence of olivine is influenced, though not totally controlled, by the experimental procedure. Olivine is present in all crystallized experiments that were initiated by heating at temperatures only moderately higher than the liquidus $\left(1505^{\circ} \mathrm{C}\right.$ - procedure 1$)$ and is absent in all but two of the experiments that were initiated by heating at the higher temperature of $1555^{\circ} \mathrm{C}$ (procedure 2). In both experiments that were initiated by heating at low and moderate temperatures and then rapidly cooled to temperatures below the liquidus in the entire charge (procedures 3 and 4, see Fig. 1), olivine is absent.
The capacity of pyroxene to grow rapidly once it nucleated is illustrated in the image of the experimental charge CPX15 in Fig. 1. Pyroxene fills the whole capsule, from the cool top, which was quenched at $1278^{\circ} \mathrm{C}$, to the hot base quenched at $1352^{\circ} \mathrm{C}$. In this charge pyroxene crystallized at temperatures far higher than those in experiment CPX10, which was entirely glassy even though it was quenched at a lower temperatures of 1269 to $1307^{\circ} \mathrm{C}$. Pyroxene is absent at the hot end $\left(1298^{\circ} \mathrm{C}\right)$ in experiment CPX09, where only olivine has crystallized. The differences in the phase assemblages can in part be attributed to the experimental conditions. The cooling rate in experiment CPX10, which produced an entirely glassy charge, was $200^{\circ} \mathrm{Ch}^{-1}$, and this rapid rate no doubt prevented nucleation. For experiment CPX15, in which the charge is totally crystallized to pyroxene, procedure 2 was used, and it is possible that the initial period of high-temperature heating destroyed the relict structures in the liquid that in other experiments facilitated the nucleation of olivine. It appears that, in experiment CPX15, no olivine crystallized at high temperatures, and once pyroxene nucleated it grew rapidly to fill the entire capsule. In experiment CPX09, conducted using procedure 1, pyroxene also nucleated and it crystallized throughout the upper two-thirds of the capsule. However, in this case it did not penetrate into the lower portion of the capsule, presumably because the composition of the liquid had been modified by the growth of the large olivine crystals.

Another aspect that needs to be emphasized is the presence of pigeonite even in rapidly cooled runs. Zoned crystals with pigeonite cores are present in experiments CPX19 and 26 , both of which were cooled at $100^{\circ} \mathrm{Ch}^{-1}$. The idea that pigeonite only forms at slow cooling rates less than $10^{\circ} \mathrm{C}$ per hour (Parman et al., 1997) is clearly not valid.

\subsection{Application to natural rocks}

One important goal of our study was to understand the conditions in which pyroxene crystallizes in komatiites. Although this goal has been realized in a broad sense, several important differences between the environment of crystallization in the interior of a komatiite flow and our experimental setting limit the application of our results. Our experiments have demonstrated how subtle differences in pre- or syn-crystallization conditions can significantly change the order of crystallization and the compositions of the phases that crystallize. In the interiors of komatiite lava flows, conditions were far less extreme than those in our experiments. For example, although it can be argued that some komatiites became superheated during their passage from mantle source to the surface (e.g., Echeverria, 1980), most komatiites contained olivine phenocrysts when they erupted, which indicates that on eruption they were effectively at their liquidus. Furthermore, in the interior of a lava flow, at tens to hundreds of centimeters beneath the flow top, cooling rates are limited by conduction through the solid crust of the flow and are relatively low. 
At depths of several meters below the flow top, the level at which pyroxene spinifex texture forms, cooling rates were below $1{ }^{\circ} \mathrm{Ch}^{-1}$ (Turner et al., 1986). The fact that we grew zoned pyroxene crystals with pigeonite cores and diopside rims in our experiments is significant because the similarity between these crystals and those in natural komatiites indicates that we have reproduced the essential features of the natural environment. In both settings the pyroxene grains crystallize during constrained growth in a thermal gradient. The growth starts at the cool end of the experimental charge or lava flow, then proceeds downwards.

Other aspects of our experimental results, such as the appearance of metastable olivine, also have application to komatiite crystallization. In thick komatiitic basalt flows in Quebec (Imreh, 1978), Finland (Hanski, 1979) and Australia (Arndt et al., 2001), centimeter- to decimeter-thick layers of olivine spinifex alternate with layers of pyroxene spinifex. The alternation can be repeated many times over intervals of a few meters. A possible explanation of this type of layering is alternate saturation in olivine or pyroxene in a manner comparable to the saturation of one of these phases or the other in our experiments.

\section{Conclusions}

- Spinifex textures result from crystallization at moderate cooling rates within a thermal gradient. Analogues of komatiitic basaltic compositions crystallize zoned crystals with pigeonite cores and diopside (or augite) margins.

- Pigeonite formed at cooling rates up to $100^{\circ} \mathrm{Ch}^{-1}$.

- Large degrees of undercooling occur at the onset of crystallization of pyroxene crystals (both pigeonite and augite).

- Under conditions of moderate cooling rates, forsterite crystallizes metastably from a liquid with pigeonite at the liquidus. If the liquid is heated to high temperatures before rapid cooling, pyroxene nucleation is strongly delayed, but once crystallization starts it proceeds rapidly.

Edited by: M. Heap

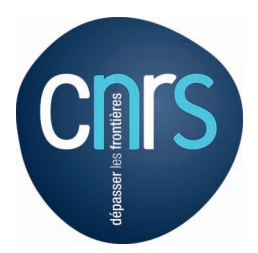

The publication of this article is financed by CNRS-INSU.

\section{References}

Arndt, N. T. and Fleet, M. E.: Stable and metastable pyroxene crystallization in layered komatiite flows, Am. Mineralogist, 64, 856-864, 1979.

Arndt, N. T., Barnes, S. J., and Lesher, C. M.: Komatiite, Cambridge University Press, Cambridge, p. 487, 2008.

Arndt, N. T., Bruzak, G., and Reischmann, T.: The oldest continental and oceanic plateaus: geochemistry of basalts and komatiites of the Pilbara Craton, Australia, in: Mantle Plumes: their identification through time, edited by: Ernst, R. E. and Buchan, K. L., Geol. Soc. Am., Special Paper, 352, 359-388, 2001.

Bouquain, S., Arndt, N. T., Hellebrand, E., and Faure, F.: Crystallochemistry and origin of pyroxenes in komatiites and lunar basalts, Contrib. Mineral. Petrol., 158, 599-617, doi:10.1007/s00410-009-0399-0, 2009.

Campbell, I. H. and Arndt, N. T.: Pyroxene accumulation in spinifex-textured rocks, Geol. Mag., 119, 605-610, 1982.

Donaldson, C. H.: Spinifex-textured komatiites: A review of textures, mineral compositions, and layering, in: Komatiites, vol. George Allen and Unwin, edited by: Arndt, N. T. and Nisbet, E. G., London, 211-244, 1982.

Echeverria, L. M.: Tertiary or Mesozoic komatiites from Gorgona Island, Colombia; field relations and geochemistry, Contrib. Mineral. Petrol., 73, 253-266, 1980.

Faure, F., Arndt, N. T., and Libourel, G.: Formation of spinifex texture in komatiites: an experimental study, J. Petrology, 47, 15911610, 2006.

Fleet, M. E. and MacRae, N. D.: A spinifex rock from Munro Township, Ontario, J. Can. Earth Sci., 12, 928-939, 1975.

Hanski, E. J.: Komatiitic and tholeiitic metavolcanics of the Siivikkovaara area in the Archean Kuhmo greenstone belt, eastern Finland, Geol. Soc. Finland Bull., 52, 67-100, 1979.

Imreh, L.: Album photographique de coulées meta-ultramafiques sous-marines achéennes dans le sillon de La Motte-Vassan [Photographic album of submarine Archean meta-ultramafic flows in the LaMotte-Vassan belt], Ministere des Richesses naturelles, Rapport V-6, 131 pp., 1978.

Kinzler, R. J. and Grove, T. L.: Crystallization and differentiation of Archean komatiite lavas from northeast Ontario: phase equilibrium and kinetic studies, Am. Mineral., 70, 40-51, 1985.

Lofgren, G. E.: Effect of heterogeneous nucleation on basaltic textures: A dynamic crystallization study, J. Petrol., 24, 229-255, 1983.

Longhi, J. and Boudreau, A. E.: The orthoenstatite liquidus field in the system forsterite-diopside-silica at one atmosphere, Am. Mineral., 65, 563-573, 1980.

Parman, S., Dann, J., Grove, T. L., and de Wit, M. J.: Emplacement conditions of komatiite magmas from the 3.49 Ga Komati Formation, Barberton Greenstone Belt, South Africa, Earth Planet. Sci. Lett., 150, 303-323, 1997.

Turner, J. S., Huppert, H. E., and Sparks, R. S. J.: Komatiites II: Experimental and theoretical investigations of post-emplacement cooling and crystallization, J. Petrol., 27, 397-437, 1986. 